\title{
Using videoconferencing mediated mentoring to support an adjunct faculty
}

\begin{abstract}
Jale Aldemir $^{1}$ and Jillian Ardley ${ }^{2}$
Abstract: Mentoring is an effective way to orient new employees to an organization's work climate. Many colleges operating in multiple locations and providing programs for working adults through evening classes rely on the expertise of adjunct faculty to provide instructional methods. The research literature about mentoring in a higher education context mainly focuses on mentoring full time faculty members. Therefore, this case study is believed to address the gap as it focuses on understanding the mentoring of adjunct faculty. The researchers of the present study believe that utilizing videoconferencing as a tool to mentor new adjunct faculty could be beneficial in the context of any college serving in multiple sites. The purpose of the study is to (a) to determine if videoconferencing is an effective tool in mentoring adjunct faculty, and (b) to determine if videoconferencing mediated mentoring (VMM) is effective for full time faculty in disseminating the strategies and skills to qualified adjunct faculty. VMM implemented in the study includes essential segments - pre-course professional development section, interim course hands-on training and support section, and the post course section to evaluate findings. Data analysis through mentor and mentee logs and surveys proved that VMM is a valuable medium to utilize for training purposes. This type of technology provides a platform for the full time faculty member to build a professional relationship and share the standard of excellence for a given field of study to new adjunct faculty member.
\end{abstract}

Keywords: Videoconferencing; Teacher Education Faculty

\section{Introduction}

Mentoring a novice colleague is possibly one of the oldest educational methods that exist for supporting a new coworker. It is an effective way to coach new employees and help them orient to the organizations' work climate. In general, “... mentoring is a reciprocal learning relationship characterized by trust, respect, and commitment, in which a mentor supports the professional and personal development of another by sharing his or her life experiences, influence and expertise" (Zelles, Howard, \& Barcic, 2008, p. 555). Therefore, mentoring is a viable component of professional development in an organization.

In the context of higher education, the traditional method of mentoring is to formally assign a senior faculty member who is considered to be knowledgeable, skilled, and experienced to a new faculty member in order to prepare the new colleague for the academic and research demands of the college. Although the format of this relationship is commonly structured around face to face interactions, Videoconferencing can be used as a conduit to mentor a new adjunct faculty member. Technology has already been utilized as a possible tool in the mentoring process

\footnotetext{
${ }^{1}$ Assistant Professor of Early Childhood Education at the University of North Carolina Wilmington, aldermirj@uncw.edu

${ }^{2}$ Associate Professor of ECE at Mount Olive College, jardley@moc.edu
} 
where mentors and mentees can meet to discuss topics of interest even when they are not in the same location (Loureiro-Koechlin \& Allan, 2010). Specifically, by observing, and participating with, a full time faculty member who is situated in another site and has years of experience in planning and teaching within this framework, mentoring a new faculty can transpire.

Colleges are no longer just brick and mortar with colleagues in the same building. Today, many colleges also operate in multiple locations and provide programs for working adults through evening classes that rely on the expertise of adjunct faculty to produce instructional methods to help those students reach educational goals set by the institutions. However, increasing competitiveness in serving more students in multiple sites brings the issue of having adjunct faculty who may not be familiar with program expectations, characteristics of the student body which the college serves, or content specific pedagogical strategies and college wide procedures (Anderson, 2007).

An adjunct is an "assistant or another; a faculty member of a college or a university" (Merriam-Webster's Collegiate (R) Dictionary, 2004). As a member of the teaching body of an institute of higher education, an adjunct is a crucial component to a student's higher education academic success. In fact, Meixner and Kruck (2010) showed no significant difference between full time and part-time faculty in terms of student learning outcomes and student evaluation; however, it is indicated that those two faculty bodies are separated in the area of institutional support they receive. Furthermore, research (Bergmann, 2011; Meixner \& Kruck, 2010) points to the areas in which adjunct faculty need support such as utilizing technology, curriculum development, learning activities and strategies, assessing student learning, emotional connection with their respective programs, and finally, receiving mentoring from a senior faculty in their program of study.

Although the research literature includes various studies about mentoring in a higher education context (Bryant-Shanklin \& Brumage, 2011; Budge, 2011; Knippelmeyer \& Torraco, 2007), those studies mainly focus on mentoring full time faculty members. There is not a significant amount of research specifically focusing on mentoring adjunct faculty throughout higher education literature. Therefore, we believe that this case study contributes to the process of closing the gap in our knowledge about mentoring new adjunct faculty in a higher education context.

\section{Videoconferencing as a Tool to Mentor}

Kent and Simpson (2010) define the term videoconferencing "as a system where two or more participants in different locations can interact using specialized equipment through highspeed internet connection" (p. 13). It is a real time media platform in which all participants can share thoughts and information visually as well as verbally in a long distance format. Videoconferencing has been widely used across different disciplines for various purposes such as training of medical personnel, in-service teacher education, $\mathrm{K}$ to 12 students' instruction, and pre-service teacher education (Kent \& Simpson, 2010; Knight, Pedersen, \& Peters, 2004; Nudell, Roth, \& Saxowsky, 2005; Saurino et al., 1999). For example, Hare and Eaton (2010) evaluated a training project that was conducted through videoconferencing. The project aimed to train volunteer literacy tutors for speakers of English as an additional language (EAL). The study adopted a "participatory evaluation" (PE) system in order to draw a complete picture about the success of the project, and issues, concerns, and challenges during the process. Furthermore, all stake holders (i.e., literacy tutors, site facilitators, instructors, technical support personnel, 
evaluators, and observers) input their evaluations about the study. The benefits the trainees gained from the study were that this method was cost and time effective because it was delivered to the tutors living in remote areas and that this strategy saved the volunteer tutors from commuting to the main location to receive the training.

Melnky (2012) reports from medical field studies that combine different technology based support systems with videoconferencing in order to promote better patient outcomes in training of medical personnel. Despite the plethora of research utilizing technology as a means to support learning, research to determine the effectiveness of using videoconferencing to train instructors to model best practices is limited. Even though various entities such as the medical field and governmental agencies are mandating the use of videoconferencing as a training tool, "the evidence on their efficacy and cost benefits is still inconclusive as to whether the cost and the benefits represent the best value for the dollars invested" (Melnky, 2012, p.63). Therefore, videoconferencing mediated mentoring (VMM) is proposed to add to the growing body of evidence.

\section{Purpose of the Study}

An efficient manner for mentoring new adjunct faculty at diverse locations of a college by a fulltime faculty member is the rationale for the study. The early childhood education (ECE) program of a southeastern North Carolina college where the first author was former faculty and the second author is currently faculty used to hold biyearly adjunct faculty meetings to orient new faculty into the college and keep existing adjunct faculty up-to-date with changes, and improvements in the college and the student body that they were serving. However, with recent changes such as the length of each course modified to five weeks, and the addition of a licensure track program to the existing non-licensure track, there is an increasing demand for more adjunct faculty to teach early childhood education courses at the multiple sites the college has throughout southeastern North Carolina. Unfortunately, due to budget cuts, bi-annual orientation meetings for adjunct faculty are no longer conducted by the college. Considering these circumstances, the researchers of the present study believe that utilizing videoconferencing as a tool to mentor new adjunct faculty could be beneficial in the context of any college serving in multiple sites. Adjunct faculty can benefit from instruction from those with expertise in their respective field via video conferencing technology.

The purpose of the study is two-fold: (a) to determine if videoconferencing is an effective system in mentoring adjunct faculty in the strategies and skills required to teach courses that they were credentialed to teach by the college, and (b) to determine if videoconferencing mediated mentoring (VMM) was an effective system for full time faculty in disseminating the strategies and skills to qualified ECE adjunct faculty.

\section{Methodology}

The researchers employed a qualitative case study method. Stake (1995) indicates that a "Case study is the study of the particularity and complexity of a single case, coming to understand its activity within important circumstances" (p. xi). In the present study, the researchers proposed to explore videoconferencing as a method for mentoring adjunct faculty, and to determine how this method can be formulated in the future to orient and mentor newly hired adjunct faculty. This case is also an "instrumental" case study (Stake, 1995) in the sense 
that one can a) observe and study the effects of videoconferencing on the mentoring process, and b) review and improve the orienting and mentoring procedures for adjunct faculty.

\section{Participants}

Two early childhood faculty members, one adjunct and one full time, at a Southeastern North Carolina College participated in the study. The adjunct faculty member who was new and qualified to teach educational psychology courses, was contacted via email and invited to participate in the study because he did not have prior experience in teaching in a 5-week course format or ECE students. The full time faculty member, who had expertise in teaching working adults in 5-week course model, participated in the study. This participant developed and taught the course used for the study multiple times.

\section{Research Procedures}

The study took place in the context of one of the Early Childhood Education courses, EDU 351-Psychological and Sociological Foundations of Education. Two early childhood cohorts in two sites of the college synchronously enrolled in the same course. Both cohorts were assigned to a classroom with videoconferencing capability to conduct the study. The videoconferencing equipment was Polycom Videoconferencing Codecs, which included two cameras around the room, a microphone attached to the instructor's desk, multiple microphones hanging from the ceiling to capture the sound throughout the room, and a 42 " TV in the rear of the room as well as a 60 " $\times 60$ " projection screen at the front of the class.

One of the data collection methods adopted in this study was weekly logs collected by the faculty mentor and the mentee. The mentee was required to write a weekly log pertaining to how VMM supported his understanding of best practices for an adjunct instructor. The faculty mentor was required to write a weekly log pertaining to her understanding of transmitting best practices to a new adjunct faculty via VMM. These logs were documented on a word processor soon after each session. The mentee delivered the weekly log at least two days prior to the next session to help the faculty mentor reassess the mentee's needs and prepare for the session accordingly. Finally, the logs were delivered to the evaluator for data analysis.

The research model also included an evaluator who did not participate in the interactions between the participants. The evaluator was a faculty member at the same college who had prior experience in videoconferencing research. The purpose of the evaluator was to observe the interactions between the participants, collect the data, and triangulate findings with the participants at the conclusion of the coursework.

Another data collection method used in this study was a two-part survey. One part consistent of a Likert scale and part two consisted of open-ended survey questions. The evaluator conducted the surveys upon the completion of the course in which the study was conducted. The evaluator also met with each participant individually and recorded the results. Data was analyzed by using the "Constant Comparative" (Glaser \& Strauss, 1999) method to discover the emerging relations and issues across different data resources.

The research protocol consisted of three parts. This included, a) prior/preplanning section, b) interim/during the course section, and c) post/after the course completion section. These sections are detailed in Videoconferencing Mediated Mentoring (VMM) model in Table 1. 
Table 1

Videoconferencing mediated mentoring (VMM) model

\begin{tabular}{|c|c|c|}
\hline Timeline & Mentor & Mentee \\
\hline 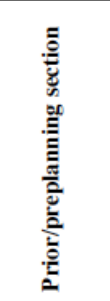 & $\begin{array}{l}\text { - The experienced faculty (mentor) is assigned to their } \\
\text { respective location. } \\
\text { The mentor receives a technical training from IT prior to } \\
\text { course start to learn the features of the videoconferencing } \\
\text { equipment in their assigned classroom. } \\
\text { - The mentor trains the mentee on overall structure } \\
\text { Moodle online student support system. }\end{array}$ & $\begin{array}{l}\text { The adjunct faculty (mentee) is assigned to their } \\
\text { respective location. } \\
\text { The mentee receives a technical training from the } \\
\text { mentor prior to course start to learn the features of } \\
\text { the videoconferencing equipment in their } \\
\text { classroom. } \\
\text { - The mentee receives training from the mentor on } \\
\text { overall structure of the course, syllabus, course } \\
\text { expectations, utilizing Moodle online student } \\
\text { support system. }\end{array}$ \\
\hline 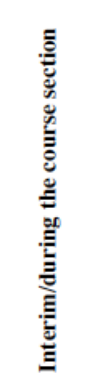 & $\begin{array}{l}\text { - Course agenda, lectures, handouts and tests are prepared by } \\
\text { the mentor. } \\
\text { Before each session the faculty mentor communicates to the } \\
\text { mentee via phone to discuss the session agenda, instructional } \\
\text { strategies, and classroom activities to engage the learners in } \\
\text { both sites. } \\
\text { - The mentor teaches majority of the sessions to the remote site } \\
\text { via videoconferencing. } \\
\text { - The mentor models teaching pedagogy appropriate for early } \\
\text { childhood education concepts in the context of } \\
\text { the course. } \\
\text { - The mentor and the mentee debrief after each session via } \\
\text { phone, texting and email. }\end{array}$ & $\begin{array}{l}\text { - The mentee receives the course materials from the } \\
\text { mentor prior to each session. } \\
\text { The mentee receives orientation from the mentor on } \\
\text { the session agenda prior to each class. } \\
\text { The mentee observes the mentor's instruction. } \\
\text { The mentee intermittently teaches their class and } \\
\text { the remote site (mentor's site). } \\
\text { - The mentor and the mentee debrief after each } \\
\text { session via phone, texting and email. }\end{array}$ \\
\hline 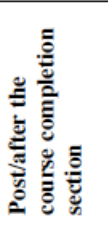 & $\begin{array}{l}\text { The mentor completes a survey and share their } \\
\text { final thoughts with the mentee and the evaluator after the } \\
\text { course ends. } \\
\text { The evaluator takes logs and surveys and analyzes findings } \\
\text { from the mentor's data. }\end{array}$ & $\begin{array}{l}\text { - The mentee completes a survey and share their final } \\
\text { thoughts after the course ends with the mentor and } \\
\text { a researcher. } \\
\text { The evaluator takes the logs and surveys and } \\
\text { analyzes the findings from the mentee's data. }\end{array}$ \\
\hline
\end{tabular}

Upon the completion of the study, the following procedures occurred to analyze the data: First, the evaluator watched each session as well as checked each recording to ensure that each participant followed the study procedures. Second, the evaluator collected the data (e.g., logs, mentor survey and mentee survey, session recordings). Third, the evaluator and the faculty mentor independently reviewed and analyzed the data to note emerging themes. Fourth, the evaluator conferenced with the mentee to validate the emerging themes, areas of strength and needs noted from the logs and survey. Finally, the evaluator conferenced with the faculty mentor to validate the emerging themes, areas of strength and needs noted from the logs and survey. Using an evaluator ensured the triangulation of the data collected from each participant.

\section{Findings}

Videoconferencing was used as a medium to mentor a new adjunct faculty in this case study. Specifically, this technology was used to support an adjunct faculty who did not have experience in teaching an evening early childhood education course in his credentialed area by observing, and participating with, a full-time faculty member who was located in another site and had years of experience in planning and teaching within this framework. Therefore, the videoconferencing mediated mentoring (VMM) model (Table 1) was followed to mentor the new faculty. After the course completion, the mentor and the mentee completed a survey that included rating questions about teaching through videoconferencing and open-ended questions about mentoring through videoconferencing. The mentor and mentee logs and open-ended 
Aldemir, J. \& Ardley, J.

survey questions filled by the mentor and the mentee upon the completion of the study shed light on whether or not this model was effective. Table 2 shows the mentor's and mentee's responses to the open-ended questions from the survey:

Table 2

Responses to Survey Questions

Open-ended Survey Questions

Q1. Did the use of tele-education for this course offer any advantages over face-to-face training with experienced faculty? If yes, explain.

Q2. Did the use of tele-education for this course offer any disadvantages over face-to-face training with experienced faculty? If yes, explain.

Q3.Were you able to see enough of the other classroom setting to facilitate instruction appropriately? If no, explain.

Q4. Did the use of tele-education for this course offer any advantages over face-to-face training of faculty new to a course? If yes, explain.

Q5. Did the use of tele-education for this course offer any disadvantages over face-to-face training of faculty new to a course? If yes, explain.

Q6.Other comments

\section{Mentor's responses}

Yes I think it offered the students in the other site with the new faculty the ability to ask questions to the experienced faculty. Those questions were related to mostly the ECE profession, which the new faculty had little experience.

The disadvantage I would mention about this is not having the face to face time to reflect on the sessions. We tried to do this through phone conversations but in my opinion face-to-face meetings would have been more productive.

I was partially able to see the other classroom. However, because of the limited videoconferencing technology, I was not able to hear or see the students' expressions.

Giving perspective about how this course could be taught with early childhood education emphasis

Orienting an instructor whom I cannot meet personally

Observing how the new faculty is teaching and offering suggestions to the instructor

Because of the technology it was not possible to read the person's body language and feelings.

Some Face to face training could be given effective such as for demonstrating the purpose of Moodle

\section{Mentee's responses}

I must say that there wasn't much that I liked about this experience. Except, I did enjoy learning from the lead instructor because how she taught the class.

I personally thought that the way the available technology was situated made it cumbersome in teaching this class.

Once again, due to the electronic set up, I was somewhat limited to what I could see in the other classroom.

The only advantage that I gleaned from this experience was viewing how the lead instructor was facilitating this class.

I felt the disadvantages outweighed the positive points.

If the technology that was being utilized would have been seamless, then I feel that it would have gone smoother. There was a delay in the transmission of the images and a slight delay in the sound. 
One of the purposes of this study is to examine whether or not videoconferencing is an effective system in mentoring adjunct faculty in the strategies and skills required to teach courses that they were credentialed to teach by the college. Both participants expressed their frustration with the inadequate videoconferencing technology in their survey responses (Table 2). Their logs also revealed some frustration over the problems the videoconferencing equipment in their respective sites. Nevertheless, the authors conclude that the ultimate goal of the VMM model, which is to mentor a new faculty in best practices to teach a course to non-traditional student, was accomplished in spite of the technological difficulties. This point is evident in the mentee's responses to the Q1 and Q4. The faculty mentor also had many challenges with the videoconferencing equipment during the study, but the advantages of mentoring through teleeducation were evident in Q4.

\section{Emerging Trends}

The data from the mentor's and mentee's logs further revealed the following important benefits of the VMM model (Table 1).

\section{Establishing a Trustful Relationship}

Given the distance between the mentor's and mentee's respective locations and the lack of funds to reimburse the faculty mentor's travel, traditional face to face meeting was not an option for both instructors to get acquainted with each other. Therefore, both parties had to rely on the technology for the first encounter. Consequently, the faculty mentor and the mentee met the first time through a videoconferencing session to orient the mentee on academic aspects as well as the technical aspects of the course. This session was very crucial to establish a relation that is based on trust and respect, and to set the tone for the remainder of the process.

During this session, each individual could see and hear the other clearly. During the introductions, similar interests and hobbies were noted which definitely established a collegial working condition. For example, the mentee noted that the faculty mentor came from a country in which he had traveled to and began introducing himself in her native language. The faculty mentor responded in the same language and applauded him on his knowledge. Next, background was given on their past experiences with the mentor's native country and a positive tone of appreciation for the other was set via video conferencing. Such an exchange helped the faculty mentor as noted in Q. 4 to develop a personal relationship with the mentee prior to working collaboratively.

According to the VMM model (Table 1), the faculty mentor had to go through a training on the videoconferencing equipment via the IT department prior to the mentee's orientation to the course. Then, the faculty mentor conducted a three-hour videoconferencing orientation session with the mentee. Both instructors documented their positive experiences in their weekly logs. For example, the faculty mentor wrote, "Overall the training went well in my opinion. Although I had only one session to learn all the features of computer and the video conferencing equipment in the class, I felt very comfortable in explaining to him all the steps to connect to the other site, using the video conferencing panel, etc." On the other hand, the mentee mentioned, "I felt the training was effective and covered the basics of how this course will be presented." Subsequently, the preplanning step of the VMM model proved to be effective in helping the 
mentee recognize the mentor's humanity as well as expertise in the subject matter as well as pedagogical methods to teach the course.

\section{Mentoring to Teach Non-traditional Course Format}

The program syllabi for the ECE courses taught in this institution are prepared as booklets, which are approximately 10 to 30 pages including all the assignment rubrics and supporting documents. They are developed by the full time faculty and no changes can be made without the approval of the full time faculty. Therefore, the course content and expectations can be maintained in a standard level throughout all locations of the college. But this still leaves a void in mentoring new faculty.

The ECE courses are typically provided in a one night a week manner for the duration of 5-week course in four-hour individual sessions. In order to maintain seamless course delivery practices, it is essential that the new adjunct faculty understands appropriate practices for teaching working adults as well as executing the expectations of the ECE degree program and the college for delivering these services. Therefore, it was necessary to communicate to the mentee the syllabus, course objectives, course content, nature of the assignments, and rubrics prior to course start date. The pre-course training as well as the mentee's ability to observe the duration of the course gave the mentee time to view and ask question about the nontraditional learning format. The ability to view and question the process of teaching and learning would have not been addressed if the syllabus was just transmitted in the usual format via email to the new adjunct faculty.

\section{Mentoring to Form an Early Childhood Perspective}

The second part of the VMM model aimed to mentor the mentee in instructional tasks required by the course. The faculty mentor prepared detailed agenda for each session, Power Point presentations, lecture notes, in-class activities, and tests. The mentor also modeled instructional methods that are typically utilized in early childhood program courses such as collaborative small group activities, student-led group presentations, classroom discussions and debates. All of these techniques were modeled in week one and two of the course. Then, after debriefing, the mentee was encouraged to practice and lead the activities in session four and five in order to enhance his understanding of implementing an ECE perspective in teaching adult learners.

The mentee of this course has a background in psychology, which qualified him to teach an educational psychology course in the ECE program. The fact that he does not have a background or experience in early childhood education was considered as a potential problem area that needed to be addressed during the mentoring process. Therefore, the faculty mentor showed an extra effort to make an early childhood connection in the instructional materials. This strategy proved to be one of the most effective findings of this model. After the first session, the faculty mentor wrote:

I hope that the materials I prepared for the night and the detailed agenda, handouts were useful for [the mentee]. I also hope that he can see that although this course is a general educational psychology course, I tried to teach the concepts from early childhood perspective. I included examples from ECE in the agenda so that [the mentee] can use them in his future teaching of this course. 
At the end of the course, the mentee explained, in his weekly log, that "Many of the examples that Dr. [Author] used were excellent, which in turn, gave me great insights and ideas that I will use in the future."

As the result of modeling early childhood connection, the mentee started to make referrals to the students' field observation papers during the session he taught. Finally, the faculty mentor and the mentee also corresponded after each session to debrief if the instructional materials worked well and brainstorm what they could do to improve them in the next session.

\section{Scaffolding the Mentee}

One of the purposes of mentoring a new colleague is to scaffold the individual to a level that he or she can reach an independent performance level. In this case study, the faculty mentor supported the mentee through two methods: 1) Providing the instructional materials, and 2) guiding the mentee to support students' learning.

First, the faculty mentor prepared the instructional materials in great detail so that the mentee could teach a session independently in case the connection to the remote site failed. In fact, this was experienced in one of the sessions in which the connection to the remote site was not successful and the videoconferencing equipment did not work. Both instructors had to teach off-line in their respective locations. The faculty mentor instructed the IT personnel who was present during each session of the course to record the mentee's session and sent the link to the mentee. The mentee shared the session link with his students to allow them to review the course content again. The faculty mentor documented this incident in her log as:

We could not get any streaming. [IT personnel] played with the band width but the network in [Location 1] was very slow tonight therefore the streaming through [Location 2] was not good. I immediately called [the mentee] and told him that he needed to conduct the session by himself. I asked him if he was prepared for the night. He said yes. I gave him instructions about the test time and told him in which content we should end the night so that we could be on the same page.

Second, the faculty mentor provided guidance to the mentee to support the students' learning. Because of the modular, fast pace of the program, it was very important for the mentee to support student learning outside of the class as well as in the class. This included a multitude of strategies. For example, the faculty mentor instructed the mentee on making instructional materials available for students after each class through Moodle so that they could review them after the class and before the exams. The mentor also prepared study guides and had the mentee make it available to his students on Moodle. Finally, the mentor introduced the companion website for the book to the mentee who then uploaded the link to the companion website on his Moodle site and made it available for his students.

Because of the initial mentor/mentee relationship established, guidance process worked well. The faculty mentor stated:

[The mentee] was to present the first agenda item. He typically followed what I prepared in the instructor's notes and the power point. Although I could not see him on the screen, he was very good at presenting the subject. Time to time, I interrupted his presentation to insert extra comments. In my opinion, he took this very constructively and I admire him for that. He did not show any resentment about this. 
About the same session, the mentee wrote, "I felt this night of class went the best so far. I began the facilitation of the class tonight for both sites; then, much like a tag team, we traded off who was teaching our respective parts."

The faculty mentor also used other means of technology to guide the mentee when videoconferencing equipment was not available.

I am grateful for the cell phones and instant message capability. Although the videoconferencing equipment did not work, we were still able to communicate. Later in the first hour, he texted and asked if he should answer the test questions. I told him that I usually do this so that it could be another learning opportunity for the students.... In our phone conversation after the streaming was broken in [the mentor's site] I told him to remind the students to use the companion website.

Even though the faculty mentor trained the adjunct faculty mentee on the Moodle online student support system, the mentee had some issues adjusting to the appropriate use of Moodle throughout the course sessions. The faculty mentor, in her journal, indicated that, "He had a problem in uploading the power point presentation to the Moodle site. I remember training him on this subject, but becoming proficient in technological student support systems takes time for some instructors as I experienced this with my other adjunct faculty." The mentor helped the adjunct faculty prepare his Moodle site. The full time faculty mentor had previously trained many adjunct faculty members in using Moodle as a student support system. Therefore, she was very experienced in guiding the mentee through the shortcuts, to make his experience with Moodle easier. Also, due to the model set in place within this study, the adjunct faculty mentee had a mentor in place to support the integration of teaching tools appropriately within Moodle.

\section{Discussion}

This case study allowed researchers to determine if videoconferencing was an effective tool in (1) mentoring an adjunct faculty in the strategies and skills required to teach courses that they were credentialed to teach by the college, and (2) to determine if videoconferencing mediated mentoring (VMM) was effective for full time faculty in disseminating the strategies and skills to a qualified adjunct faculty.

The findings for research question one indicates that VMM was an effective tool for both the faculty mentor and the mentee. First, the model allowed the participants to build a relationship prior to a professional collaboration. Second, by watching the faculty mentor the mentee was able to understand how to infuse an ECE perspective in an educational psychology course even though ECE was not his area of expertise. Third, the model supported the mentee in understanding how to help ECE students within a fast-paced non-traditional teaching model.

The findings for research question two indicates that the VMM model was effective in supporting the mentoring process due to its ability to support in real time teaching demonstrations and scaffolding through debriefing sessions using technology. VMM in the precourse training gave the mentor an opportunity to share information to the mentee. This allowed him to ask questions as they came up during the training which would have not been addressed if the syllabus was just transmitted in the usual format via email to the new adjunct faculty. VMM in the interim portion of the course allowed the mentor to set the pace and control the quality of the course through consistent feedback and modeling best practices. VMM in the post section allowed the faculty mentor to reflect on her mentoring capabilities and evaluate what worked and what needed to be improved to support mentees in the future. 


\section{Implications}

Organizing training sessions through VMM for new adjunct faculty by full time faculty in individual programs at colleges or universities that consist of multiple sites can be advantageous in many ways. First, it allows the full time faculty to connect, meet, and work with new adjuncts at remote sites in a cost effective manner. Second, it can be an effective way of acclimating the new adjunct to the program by reviewing specific expectations, curriculum, and program or college policies as well as resources that they can use in their teaching. Third, VMM has the potential to support collegiality among seasoned and novice faculty members to reduce turnover rate in faculty due to lack of academic support, ultimately contributing to the consistency and quality of the education provided to students.

Videoconferencing mediated mentoring can be utilized to improve a mentee's knowledge of the area of study. For example, the mentee of this case study's professional background is in psychology, which qualifies him to teach an educational psychology course in the ECE program. However, it is beneficial to have the content specific knowledge when teaching a course. Subsequently using VMM to observe a full-time faculty mentor who has former training and experience in a specific content area allows adjunct faculty a vicarious learning experience and material that they can catalog to utilize when they teach independently.

The teaching load of the full time faculty mentor should be modified during VMM for a variety of reasons. Developing and agenda and planning for each videoconferencing session takes a great deal of preparation because the full time faculty understands that quality training for the mentee means a higher possibility of quality teaching for the present and future classes within the program of study. The full time faculty mentor also supports the mentee with materials and handouts and step by step instructions for each session, including calculation of the time that might be spent on controlling videoconferencing (e.g., switching between screens, muting and unmuting, audio control, zooming cameras, etc.) equipment. Therefore, we recommend a modified teaching schedule/load for the mentor and the addition of an hour long preplanning VMM session each week so that the mentor and mentee can work collaboratively on instructional materials to support their individual classes' learning styles and needs.

Colleges need to provide appropriate technical support and quality equipment to support successful VMM. Unstable, changing network speed could be problematic as this could seriously affect the creation of a sense of community across remote sites. The researchers concluded that VMM requires "expertise in videoconferencing and adult education, technical and troubleshooting knowledge, ability to bridge participants [in all location]..." (Hare \& Eaton, 2010 , p. 4). For example, because of the poor sound quality of the videoconferencing system, the students in both sites could not clearly hear or understand each other during those discussions. Therefore, in-class discussions had to be held independently in two classroom sessions. This limited the mentor's ability to model holding effective classroom discussions.

Corresponding only through videoconferencing is not sufficient during the VMM process; other means of technology could also be used by full time faculty mentor with the new adjunct faculty when one system fails or is unavailable. For example, the mentee had problems in uploading materials to the course's Moodle site prior to the second session and the videoconferencing was not on at that time or available for their use. Therefore, the full time faculty mentor instructed the adjunct faculty mentee on the phone to upload those materials to the online site. 
Debriefing is an important strategy in the VMM process. The full time faculty mentor and the adjunct faculty mentee debriefed after the each session to reflect their thoughts about the session. This was very useful for the mentee as well as the mentor in terms of discussing what went well and what could be done to improve it. We recommend that the debriefing process could be improved by adding another dimension. The mentee's teaching during the VMM training period in his/her class sessions could be recorded via videoconferencing equipment and used for debriefing purposes. Recordings would allow mentor and mentee to revisit the concepts taught, instructional methods used, and overall pedagogy the mentee reflected throughout his/her teaching.

The findings of this case study can only be generalized to the context in which it was conducted. However, the researchers believe that the points discovered from the study can have implications for future efforts to mentor adjunct faculty by using videoconferencing technology through the VMM process. VMM could be a very productive time and money saving tool. It helps connect experienced faculty with novice faculty who are not able to meet physically because of their locations or budget constraints within a technological communication platform. Furthermore, it helps develop a sense of community between colleagues who previously were known only by their name and credentials within the program of study in order to standardize the quality of the instruction throughout multiple sites of a university.

\section{References}

adjunct 1 a-j(k)t. (2004). In Merriam-Webster's Collegiate(R) Dictionary. Retrieved from http://ezproxy.moc.edu/login?qurl=http $\% 3 \mathrm{~A} \% 2 \mathrm{~F} \% 2 \mathrm{Fwww} . c r e d o r e f e r e n c e . c o m / e n t r y / m w c o l l e g i$ ate/adjunct_1_a_j_k_t

Anderson, D. C. (2007). Mentoring new adjunct faculty to teach science laboratories. Journal on Excellence in College Teaching, 18 (2), 61-78.

Bergman, D. M. (2011). A study of adjunct faculty (Doctoral dissertation). Retrieved from http://etd.lib.montana.edu/etd/2011/bergmann/BergmannD0811.pdf

Bryant-Shanklin, M., \& Brumage, W. N. (2011). Collaborative responsive education mentoring: Mentoring for professional development in higher education. Florida Journal of Educational Administration \& Policy, 5(1), 42-53.

Budge, S. (2006). Peer mentoring in post-secondary education: Implications for research and practice. Journal of College Reading and Learning, 37(1), 73-87.

Glaser, B. G., \& Strauss, A. L. (1999). The discovery of grounded theory: Strategies for qualitative research. Hawthorne, NY: Aldine De Gruyter.

Hare, C., \& Eaton, S. (2010, January). Evaluation of videoconferencing pilot project: Educating for volunteer literacy tutors for speakers of English as an additional language (EAL)- An ICCAN pilot project in collaboration with rural routes. Retrieved from EBSCO host.

Kent, A. M., \& Simpson, J. L. (2010). Interactive videoconferencing: Connecting theory to 
practice for preservice teachers. Journal of Digital Learning in Teacher Education, 27(1), 12-21. doi:10.1080/21532974.2010.10784652

Knight, S. L., Pedersen, S., \& Peters, W. (2004). Connecting the university with a professional development school: Pre-service teachers' attitudes toward the use of compressed video. Journal of Technology and Teacher Education, 12(1), 139-155.

Knippelmeyer, S. A., \& Torraco, R. J. (2007, March). Mentoring as a developmental tool for higher education. Paper presented at the Academy of Human Resource Development International Research Conference in The Americas, Indianapolis, IN.

Loureiro-Koechlin, C., \& Allan, B. (2010). Time, space and structure in an e-learning and ementoring project. British Journal of Educational Technology, 41(5), 721-735. doi:10.1111/j.1467-8535.2009.00975.x

Meixner, C., \& Kruck, S. E. (2010). Inclusion of faculty for the benefit of faculty and students. College Teaching, 58, 141-147. doi:10.1080/87567555.2010.484032

Melnyk, B. (2012). The role of technology in enhancing evidence-based practice, education, health care quality, and patient outcomes: A call for randomized controlled trials and Comparative. effectiveness research. Worldviews On Evidence-Based Nursing 9(2), 63-65. doi: $10.1111 / \mathrm{j} .1741-6787.2012 .00245 . \mathrm{x}$

Nudell, D., Roth, B., \& Saxowsky, D. (2005). Non-traditional extension education using videoconferencing. Journal of Extension Education, 43(1). Retrieved from http://www.joe.org/joe/2005february/tt3.shtml

Ritzel, D. O. (2010). International videoconferencing: A reaction to Burke et al. American Journal of Health Education, 41(1), 62-64. doi:10.1080/19325037.2010.10599128

Saurino, D. R. et al. (1999, March). Preparing science teachers using distance learning: Urban and rural students collaborate using video teleconferencing (VTEL) technology. Paper presented at the Annual Meeting of the National Association of Research in Science Teaching, Boston, MA.

Stake, R. E. (1995). The art of case study research. Thousand Oaks, CA: Sage.

Zelles, D. F., Howard, V. M., \& Barcic, M. A. (2008). Faculty mentoring programs: Reenvisioning rather than reinventing the wheel. Review of Educational Research, 78(3), 552588. doi: $10.3102 / 0034654308320966$ 